\title{
IMAGEM AMADORA NO TELEJORNALISMO EM TEMPOS DE CULTURA DIGITAL
}

\section{THE AMATEUR TELEJOURNALISM IMAGE IN TIMES OF DIGITAL CULTURE}

Fábio Bitencourt Cadorin

\author{
Doutor em Ciências da Linguagem pela Universidade do Sul de Santa Catarina \\ Graduado em Comunicação Social pela Universidade do Sul de Santa Catarina \\ Professor da Universidade Veiga de Almeida \\ E-mail: fabiocadorin@hotmail.com
}

\section{RESUMO}

Este artigo investiga se a relevância do valor-notícia visualidade, no telejornalismo, sofre impacto com a implantação da TV digital. É uma síntese da tese de doutorado deste autor, intitulada "Imagem amadora no telejornalismo em tempos de cultura digital: implicações sobre o valor-notícia visualidade, na perspectiva de editores-chefes de telejornais de abrangência estadual de Santa Catarina". A pesquisa parte do pressuposto de que a realidade é um fenômeno em construção. Paradigmas construcionistas, portanto, norteiam o estudo. Dentre as teorias do jornalismo, utiliza-se o Newsmaking por abarcar conceitos fundamentais à investigação, a começar pelo valor-notícia. A opção também se dá pelo fato de a pesquisa se desenvolver na perspectiva dos emissores. O referencial bibliográfico prioriza a abordagem de aspectos relacionados à cultura digital. Analisa-se o processo de transição do analógico para o digital e como essa mudança afeta as mídias, sobretudo, a televisão. Percebe-se que a produção de imagens que alcançam ampla circulação já extrapola os limites dos veículos de comunicação de massa tradicionais. Neste contexto, inserem-se as imagens amadoras. Enfatiza-se, então, o papel do olhar amador na construção da notícia. Como técnica de pesquisa de campo, realizam-se entrevistas em profundidade com editores-chefes de telejornais de abrangência estadual de Santa Catarina. Emprega-se uma análise de conteúdo para o tratamento do corpus. Os resultados sugerem que a relevância do valor-notícia visualidade, no telejornalismo, não sofre impacto com a implantação da TV digital, mas tem a ver com o ingresso na cultura digital. Os dados também apontam para o fortalecimento do jornalismo participativo e da audiência como coautora da produção noticiosa de televisão, uma vez que a imagem amadora assume relevância além de sua utilidade como cobertura da zona de sombra do jornalismo.

Palavras-chave: imagem amadora. telejornalismo. TV digital. cultura digital. 


\begin{abstract}
This paper investigates the relevance of visuality of the news value in television journalism impacted with the implementation of digital TV. It is a doctoral thesis synthesis, entitled "Amateur Image in Television Journalism in Digital Culture Times: implications of visuality news value, in the point of view of TV news editors in statewide of Santa Catarina". The research assumes that reality is a phenomenon in construction. Therefore, constructionist paradigms guide the study. Among the theories of journalism, the Newsmaking is used to cover fundamental concepts of research, beginning from news value. The option of this research also occurs because it is developed in the perspective of issuers. The bibliographic reference gives priority to addressing issues related to digital culture. It analyzes the transition of the analogic streaming to digital; how these changes affect media, especially the television. It is noticed that the production of images that reach wide circulation already extrapolate the limits of traditional mass media outlets. In this context, the amateur images are insert. So, the role of the amateur look in the construction of news is emphasize. As field research technique, interviews with newscasts of chief editors of statewide Santa Catarina are carried out. A content analysis for the treatment of the corpus is used. The results suggest that the relevance of news value visuality in television journalism did not impacted by the introduction of digital $\mathrm{TV}$, but it connected to the entry into the digital culture. The data also point to the strengthening of participatory journalism and audience as co-author of the news television production, since the amateur image is relevant beyond its usefulness as coverage of journalism shadow zone.
\end{abstract}

Keywords: Amateur image. TV journalism. Digital TV. Digital culture.

\title{
1 INTRODUÇÃO
}

Nunca se viu, na história da humanidade, tantas imagens materializadas ou virtualmente projetadas como na atualidade. Tem sido rápido e frequente o surgimento de novos dispositivos capazes de produzir e distribuir conteúdos audiovisuais em formato digital. Esse fenômeno tem impacto direto nas práticas, lógicas e noções existentes até então sobre o protagonismo de meios como o cinema e a televisão na produção e distribuição de tais conteúdos (KILPP, 2012).

Cannito (2010, p. 15) afirma que a tecnologia digital é a maior revolução da história das mídias. "O digital é mais que uma mídia: é uma tecnologia - e, principalmente, uma cultura - que contamina todas as outras mídias”. No caso da televisão, a migração do sistema 
analógico para o digital não afeta apenas o modo de produção e exibição de conteúdos. Tem consequências sociais e econômicas. Citação da Exposição de Motivos anexa ao decreto presidencial que trata da implantação da TV digital no Brasil afirma que ela é "uma nova plataforma de comunicação, cujos impactos na sociedade ainda estão se delineando" (FERRAZ, 2009, p. 15).

Nesta pesquisa, a pergunta central situa-se no campo do telejornalismo e em sua relação com a TV digital. Entre os critérios de noticiabilidade dos telejornais, o valor-notícia visualidade sempre teve relevância, afinal, imagem é um dos elementos preponderantes da televisão. Porém, se por muito tempo a veiculação de imagens do cotidiano para grandes públicos foi praticamente exclusividade da televisão, hoje não é mais. Se cabia aos telejornais desvelar os "principais" acontecimentos do mundo, hoje, os acontecimentos estão visualmente acessíveis por vários outros meios, e a qualquer hora. E o que muda não são apenas as plataformas de comunicação, mas o fato de que a produção de imagens não depende apenas de profissionais, mas de amadores.

No contexto da cultura digital, essas imagens parecem assumir importância ainda maior, visto que se ampliam não apenas em quantidade, mas em qualidade. Sua circulação também se torna mais fácil e veloz.

Propõe-se investigar, então, se relevância do valor-notícia visualidade, no telejornalismo, sofre impacto com a implantação da TV digital.

Além do referencial bibliográfico, procura-se obter respostas por meio de uma série de entrevistas com editores-chefes de telejornais. Apresenta-se a metodologia e a técnica de pesquisa utilizadas no tópico a seguir.

\section{PERCURSO METODOLÓGICO}

O campo teórico sobre o qual se desenvolve esta pesquisa parte de um dos conceitos centrais do jornalismo, a notícia. De acordo com Alsina (2009, p. 299), "notícia é uma representação social da realidade quotidiana, produzida institucionalmente e que se manifesta na construção de um mundo possível”. Sob esta perspectiva, percebe-se que não há como retratar a realidade como um espelho. O conhecimento da realidade e todo discurso que sobre ela se faz são produtos de uma construção social. Então, o percurso metodológico aqui adotado baseia-se em paradigmas científicos que compreendem a realidade social não como fenômeno dado ou pronto, mas como fenômeno em construção. 
Sabe-se que as interações do sujeito com o mundo são, em grande parte, influenciadas pela mídia. Logo, é fácil admitir que os veículos de comunicação têm forte influência na construção social da realidade. Toda vez que um acontecimento passa pela mídia é como se adquirisse status no campo da existência. "Para que o acontecimento exista, é necessário nomeá-lo. $\mathrm{O}$ acontecimento não significa em si. O acontecimento só significa enquanto acontecimento em um discurso", afirma Charaudeau (2006, p. 31).

Quando se trata de mídia, as narrativas da realidade têm lugar, sobretudo, nos produtos jornalísticos. "Os jornalistas têm um papel socialmente legitimado e institucionalizado para construir a realidade social como realidade pública e socialmente relevante" (ALSINA, 2009, p. 47).

Sob a ótica do Newsmaking, uma notícia é sempre produto da relação entre a cultura profissional dos jornalistas e a organização do trabalho e dos processos produtivos (WOLF, 2003). Assim, é pertinente investigar se o valor-notícia visualidade, no telejornalismo, sobre impacto com a implantação da TV digital a partir do ponto de vista dos emissores. Para a pesquisa de campo, considerou-se apropriada a entrevista em profundidade, pois, conforme explica Duarte $(2005$, p. 62), trata-se de uma técnica qualitativa que permite obter, junto a um grupo de informantes, percepções e experiências sobre o tema em questão. "Nesse percurso de descobertas, as perguntas permitem explorar um assunto ou aprofundá-lo, descrever processos e fluxos, compreender o passado, analisar, discutir e fazer prospectivas".

Obedecendo-se a uma série de critérios para aplicação desta técnica, validaram-se dez informantes. O conjunto incluiu todos os editores-chefes de telejornais de abrangência estadual de Santa Catarina ${ }^{1}$.

Análise de conteúdo (BARDIN, 2010) foi o método empregado para a análise de entrevistas.

\section{CULTURA DIGITAL}

A cultura determina modos de o sujeito se perceber no mundo, mas não é estática. Diversos são os fatores que promovem mudanças culturais. A evolução técnica é uma delas. A tecnologia digital, por exemplo, abriu caminho para o surgimento de uma cultura de escala global: a cultura digital. O momento ainda é de transição, mas já se percebem efeitos extremamente significativos no modo como os sujeitos percebem a si mesmos e se identificam com o mundo a sua volta. 
A cibercultura se desenvolve na medida em que cresce o acesso e o uso das tecnologias de comunicação e de informação. É uma cultura que carrega a marca da diversidade, da mutação permanente e veloz. Castro (2011) afirma que há pelo menos sete pontos estruturais básicos para compreender o atual estágio de transição do analógico para o digital:

A passagem para a Sociedade do Conhecimento - Frente a um fluxo tão dinâmico de informações, em que o conhecimento passa por constante transformação, considera que as certezas já não são dadas e que, portanto, todos se tornam aprendizes. "Pela primeira vez na história, os jovens detêm conhecimentos (tecnológicos) e saberes que antes eram restritos aos adultos e pessoas mais velhas" (CASTRO, 2011, p. 20).

> A ampliação das informações circulantes - Castro (2011) reforça a noção de que a velocidade com que a informação circula e se modifica com a ajuda das tecnologias não tem parâmetros de comparação na história ocidental.

A imediatez das mensagens - De acordo com a autora (2011), diferentemente de meios físicos antigos, que tardavam a entrega de mensagens, hoje as informações circulam rapidamente através da internet, de forma virtual, independentemente da plataforma digital a ser utilizada para o envio;

A redução da intermediação das informações - Percebe-se que, atualmente, sujeitos sociais têm mais possibilidades de produzir informação, contestar notícias e enviar vídeos, fotos e áudios aos veículos de comunicação. Empresas de comunicação deixaram de ser para as massas a única fonte de informação e referência.

> A ampliação das plataformas tecnológicas - Conforme ressalta Castro (2011), o acesso à internet já não está restrito ao computador.

A ampliação dos espaços virtuais - Para exemplificar essa mudança, apontam-se as instituições de educação a distância, bancos e estabelecimentos de comércio virtuais, bibliotecas, museus virtuais e também espaços de entretenimento virtual, oferecidos por meio de diferentes plataformas tecnológicas.

As novas redes sociais e a construção de saberes coletivos - "Embora a sociedade digital incentive de um lado, o individualismo e o mundo virtual; de outro lado, como ponto de equilíbrio, crescem as relações solidárias, o trabalho cooperativado e a construção coletiva de saberes" (CASTRO, 2011, p. 21). 
Já o sociólogo Manuel Castells (2008) define a cultura digital a partir de seis

tópicos:

a) Ability to communicate or mix any product based on a digital common language.

b) Ability to communicate from the local to the global in real time, and vice versa, in order to blur the interaction process.

c) Existence of multiple modes of communication.

d) Interconnection of all data bases digitalized networks or the achievement of Nelson's hypertext dream with the storage and retrieving data system called "Xanadu" in 1965.

e) Capacity to reconfigure all configurations creating a new meaning in the different multilayers of the communication processes.

f) Gradual creation of a collective mind due to online work through a set of brains without any limits. At this stage, I am referring to connections between online brains and the collective mind (CASTELLS, 2008, online). ${ }^{2}$

Observa-se que é central a noção de que a cultura digital promove uma mudança profunda nos processos comunicacionais, com efeitos no âmbito da linguagem, nas relações de espaço e tempo, nas interações em rede, na criação gradual de uma "mente coletiva".

A internet é, talvez, a mídia mais emblemática da nova cultura. Conquistou tanta força a ponto de pesquisas de institutos norte-americanos e europeus apontarem tendências apocalípticas para a mídia tradicional. Algumas fazem crer que os meios de comunicação tradicionais só conseguirão sobreviver se forem para a internet (BACIN, 2006). Contudo, vê-se aos poucos que o caminho adotado é o da migração para o sistema digital. Mídias convencionais se reinventam a partir da nova tecnologia. É o caso da televisão, objeto deste estudo.

As primeiras transmissões do Sistema Brasileiro de TV Digital (SBTVD) ocorreram em 2007, mas o sistema ainda está em fase de implantação em diversas regiões do país. O desligamento total da TV analógica deve acontecer até 2018, conforme as portarias 477 e 481 , publicadas pelo Ministério das Comunicações no Diário Oficial da União, em 20 de junho de 2014 e 9 de julho de 2014, respectivamente. Sairão do ar as emissoras que não estiverem preparadas para transmitir o sinal de TV digital aberta até o prazo estipulado.

\subsection{PAÍS DA TELEVISÃO}

A Pesquisa Nacional por Amostra de Domicílios, a PNAD 2012 (IBGE, 2014), reforça a importância da televisão na vida dos brasileiros. Segundo ela, o aparelho está presente em 97,2\% dos domicílios do país. A Pesquisa Brasileira de Mídia 2015 revelou que 73\% dos 
brasileiros assistem à televisão todos os dias, com uma intensidade média de $4 \mathrm{~h} 31$ de segunda a sexta-feira, e de 4 h14 nos fins de semana. Também constatou que $72 \%$ dos domicílios brasileiros são atendidos pelo sistema de TV aberta, 23\% por antena parabólica e 26\% contam com serviço pago de TV.

Tamanho alcance não ocorre por acaso. Desde seu surgimento, nas primeiras décadas do século 20, essa tecnologia se mostrou mais sedutora e abrangente do que os veículos de que se dispunha até então. E até hoje, mesmo com a chegada de uma série de novidades tecnológicas, ainda não perdeu seu lugar cativo na maioria dos lares. Conforme justifica Ferraz (2009, p. 15), a televisão “tornou-se mais atraente do que o cinema, pois esse praticamente só oferece entretenimento, mais do que o jornal, que praticamente só oferece notícias, e mais do que o rádio, pois a TV agrega imagem ao áudio, o que permite que seu conteúdo audiovisual seja mais compreensivo".

Em relação ao objetivo, segundo a Pesquisa Brasileira de Mídia 2015, 79\% dos brasileiros assistem à televisão para se informar, 67\% como entretenimento ou diversão, 32\% para passar o tempo livre, $19 \%$ por causa de algum programa específico e $11 \%$ declaram ter esse meio como companhia.

Se a televisão e o telejornalismo, meio pelo qual tantos brasileiros se informam, são tão relevantes no país, confirma-se a absoluta pertinência de se investigar os rumos que devem tomar nesse limiar da era digital, ainda mais quando se ampliam as oportunidades de o telespectador participar da programação oferecendo conteúdo.

\subsection{OLHAR AMADOR E VISUALIDADE NO TELEJORNALISMO}

Cada veículo de comunicação tem suas particularidades. O jornalismo que se desenvolve em cada um deles, naturalmente, ajusta-se a essas características. A televisão sucedeu o rádio. Trouxe como novidade a imagem. Não por acaso o componente imagético é seu mais celebrado diferencial. Daí a importância do valor-notícia visualidade para o telejornalismo. Esse critério de noticiabilidade caracteriza-se pela existência e disponibilidade de fotografias ou filmes sobre o fato potencialmente noticiável (TRAQUINA, 2005).

O telejornal depende de um conjunto variado de imagens para compor seu conteúdo. A maior parte costuma ser produzida pelos profissionais das próprias emissoras de televisão. Porém, fatos que fogem à rotina ocorrem com frequência. E justamente por conter características como imprevisibilidade, novidade, curiosidade, entre outras, podem virar 
notícias. Mas esses fatos quebram a lógica do planejamento editorial. Geralmente, acontecem onde o profissional da notícia não está. Por isso, afirma Bacin (2006), a fonte amadora acaba se tornando o principal ponto de apoio do telejornalismo na construção de realidades oriundas da zona de sombra.

\begin{abstract}
O cinegrafista amador entra como peça de recuperação do passado perdido; dá sentido ao que está sendo visto; traz de uma zona não acessada pela mídia ilustrações que elucidam, muitas vezes, os motivos do acontecimento. Tais cinegrafistas se espalham pelo tecido social como olhos se abrindo em cada esquina; estão ali, atentos às ocorrências e com modos de ver peculiares e cada vez mais preparados com extensões flexíveis (BACIN, 2006, p. 84).
\end{abstract}

A força das imagens amadoras, segundo Bacin (2006), reside justamente no fato de romperem claramente com padrão das imagens produzidas pelos profissionais das emissoras. Elas podem ser irregulares, tortas, rápidas, desfocadas, escuras, que ainda trazem em sua narrativa o tom do imediatismo, da imagem que não precisa de explicação. Contudo, é necessário ter presente que a impressão de realidade provocada pela imagem amadora no telejornal sempre tem a mão do jornalista profissional, do editor. E essa interação parece se fortalecer à medida que avança a cultura digital. Por isso, torna-se necessário pensar como as práticas do telejornalismo podem se modificar em um cenário em que o telespectador se torna mais participativo.

Durante muito tempo se disse que o discurso da televisão era caracterizado como monólogo. De fato, a intervenção direta do telespectador sobre a programação era mínima ou nula. Porém, essa participação ganhou novo alcance e uma postura mais ativa com o avanço das tecnologias de comunicação. Contatos que se iniciaram basicamente por meio de cartas paulatinamente foram se tornando mais fáceis, passando pela comunicação telefônica, e-mail, mensagens via SMS, acesso a sites das emissoras, até os mais recentes aplicativos de comunicação instantânea por smartphone. Inovações tecnológicas, portanto, desencadearam novas formas de comunicar. É na cultura digital que se percebe uma oportunidade para o fortalecimento do jornalismo participativo.

Castro (2011) concorda que a participação mais efetiva do telespectador é reflexo do novo paradigma que surgiu para a comunicação, com a passagem do mundo analógico para o digital. Confirma que o salto da comunicação unidirecional (produção - mensagem - recepção) para a comunicação bidirecional, dialógica e interativa é uma das características mais marcantes dessa mudança. A autora diz que o ingresso na cultura digital despertou nas próprias audiências um desejo de maior participação. Essa constatação traz à tona uma questão relevante 
ao jornalismo contemporâneo: a audiência como coautora do conteúdo noticioso. Varela (2007) considera que o jornalismo participativo, ou jornalismo 3.0, é a terceira versão do jornalismo digital. Na primeira, chamada de jornalismo 1.0, houve a transmissão de conteúdo tradicional de meios analógicos ao ciberespaço. O jornalismo 2.0 deu-se com a criação de conteúdo de rede e para a rede. Já o jornalismo 3.0 socializa esse conteúdo e os próprios meios. A versão 3.0 representa a conquista dos meios de comunicação pelo público. "Quase não há ninguém que queira se manter informado e ficar calado. Muitos querem falar, difundir a própria informação, e alguns o fazem com especial habilidade" (VARELA, 2007, p. 53).

Pesquisa de Amorim (2009) concluiu que, para o público, a imagem amadora apresenta-se como mais fiel à realidade e, por isso, tende a conferir um caráter de maior autenticidade às notícias. Por partir do cidadão, ela seria destituída de marcas editoriais ou possíveis desvios de informação. Então, o jornalismo participativo configura-se útil à própria emissora, uma vez que também parece ganhar mais credibilidade junto ao telespectador.

Embora se apresente, inicialmente, sob o viés de um avanço positivo, no caminho de uma participação democrática, essa modalidade de jornalismo não é isenta de crítica quando atende a objetivos mercadológicos. A participação, neste caso, associa-se à ideia de aproximação. Ao favorecer a participação e aproximação do telespectador, a emissora estaria buscando, na verdade, estabelecer uma estratégia de marketing para fidelizar seus clientes. É o alerta que também faz Bourdieu (1997) quando diz que a aproximação do telespectador, submetida ao discurso de participação, serve como instrumento de dominação capitalista.

Independentemente dessa postura crítica - absolutamente relevante para o campo das ciências sociais e da comunicação, mas não determinante para o que se propõe investigar neste estudo -, observa-se que a forma de se fazer telejornalismo está mudando e, em grande parte, pelas novas relações com o telespectador que agora também vem se tornando produtor de conteúdo.

\section{ANÁLISE DOS DADOS}

Procurou-se obter respostas para a questão da pesquisa cruzando-se os dados do referencial teórico com as informações obtidas na pesquisa de campo. Atendendo-se aos requisitos propostos por Bardin (2010) para analisar o conteúdo das entrevistas, estabeleceram-se três unidades temáticas: (1) imagens amadoras; (2) TV digital; (3) valor-notícia. 
Da primeira unidade temática, emergiram doze categorias de análise, que correspondem à distinção proposta por Bacin (2006) para as imagens amadoras utilizadas nos telejornais, de acordo com suas origens, enquadramentos e intenções: (1.1) flagrante policial; (1.2) registro do fantástico; (1.3) olhar turístico; (1.4) denúncia anônima; (1.5) imagens em suas condições de produção; (1.6) circuitos de vigilância; (1.7) imagens de complementação; (1.8) flagrante armado; (1.9) câmera campana; (1.10) câmera alcagueta; (1.11) câmera corporativa; (1.12) câmera com o "olho do dono".

Da unidade temática TV digital, surgiram duas categorias: (2.1) som e imagem de alta definição e (2.2) interatividade.

A unidade temática valor-notícia também contou com duas categorias: (3.1) existência e (3.2) disponibilidade de vídeos e filmes.

A partir dessa estruturação, efetuou-se a análise dos dados. Apresentam-se, a seguir, os principais resultados. Alguns confirmam o que já se observa empiricamente nos telejornais. Outros apontam tendências e ajudam a refletir sobre os direcionamentos do telejornalismo com o avanço da cultura digital.

Constatou-se que todos os entrevistados utilizam em seus telejornais imagens amadoras e que essa é uma prática comum, o que sugere a confirmação da tese de Bacin (2006) segundo a qual a fonte amadora é o principal ponto de apoio do telejornalismo na construção de realidades oriundas de uma zona de sombra. Nem a qualidade técnica inferior impede o uso de imagem amadora nos telejornais. A restrição se aplica somente àquelas de conteúdo incompreensível. Mas seria absurdo pensar em utilização de imagem nessas condições mesmo em TV analógica ou em qualquer outro veículo e programa jornalístico.

Todos os entrevistados disseram ainda que há uma tendência de aumento na quantidade de imagens amadoras nos telejornais. Aqui, dá-se relevo ao que aparece nas entrevistas e corresponde ao que se observou no marco teórico em relação à cultura digital. $\mathrm{O}$ aumento na produção das imagens amadoras parece ter como consequência maior aproveitamento delas nos telejornais.

Em suas categorias, Bacin (2006) aponta critérios para o uso de imagens amadoras tendo em vista origens, enquadramentos e intenções referentes à notícia. Contudo, notou-se nas entrevistas que os editores-chefes também julgam relevante levar em conta aspectos que vão além da notícia, que se inserem como engrenagem no processo de fazer jornalismo. Sugerem que o uso de imagens amadoras nos telejornais também pode se tornar recurso para consolidar a prática de jornalismo participativo, promover a aproximação e fidelizar telespectadores, corresponder ao compromisso de trabalhar em prol do bem-estar social uma vez que, no caso de 
televisão aberta, a atividade só é possível mediante concessão pública, e até dinamizar o perfil do telejornal, privilegiando formas diferentes de se "contar a história" e abrindo espaço para outros pontos de pista.

O jornalismo participativo é um dos itens mais frequentes nos depoimentos e nessa prática há a percepção do telespectador como agente ativo, como parceiro, como coautor das notícias. Uma tendência que parece seguir um caminho de fortalecimento, como afirma Varela (2007, p. 74). "As notícias do futuro serão mais uma conversação do que uma conferência".

A interatividade aparece na pesquisa de campo como elemento que também pode favorecer a utilização de imagens amadoras nos telejornais. No entanto, pelo menos no período das entrevistas, ela ainda não acontecia em um nível esperado para a TV digital, mesmo nas emissoras de Santa Catarina que já estão adaptadas à nova tecnologia. Sem canal de retorno disponível, a interatividade se dá de forma não integrada, isto é, telespectadores ainda precisam lançar mão de outros recursos, além da televisão, para enviar conteúdo aos telejornais. Tal situação não causa estranhamento, porque o processo de implantação do sinal digital no país ainda está em andamento e a consolidação de recursos de interatividade não é condição para que o novo sistema opere. Apenas precisa-se ter esta noção para entender porque os depoimentos dos entrevistados baseados em sua experiência prática não remetem a níveis mais elevados de interatividade.

Em relação à abordagem da unidade temática valor-notícia visualidade, sinais de mudança são mais evidentes. Se existe uma produção crescente de imagens digitais e se elas tendem a ser mais utilizadas, pode-se pensar que a visualidade é um dos aspectos do telejornal que ganha novas configurações. A constatação se confirma na medida em que as imagens também se tornam disponíveis. De acordo com os entrevistados, está mais fácil ter acesso a elas por razões como convergência das mídias, maior quantidade de imagens em circulação, velocidade desse fluxo, surgimento de plataformas diversas em que são armazenadas ou facilidade de envio e recebimento de arquivos digitais.

\section{CONSIDERAÇÕES FINAIS}

O desenvolvimento da pesquisa se deu a partir da seguinte questão: "a relevância do valor-notícia visualidade, no telejornalismo, sofre impacto com a implantação da TV digital?" Como resposta e principal conclusão, oriunda de pesquisa bibliográfica e de campo, afirma-se que não. É o ingresso na cultura digital, e não a implantação da TV digital, que traz implicações sobre o valor-notícia visualidade no telejornalismo. 
Foi possível chegar a esta conclusão, principalmente, quando se confrontaram os dados do marco teórico relativos às características da TV digital e os depoimentos dos entrevistados sobre qualidade da imagem e interatividade na TV digital. A transmissão de som e imagem de alta definição e a ampliação de recursos de interatividade seriam dois fatores potencialmente decisivos para influenciar a utilização ou não de imagens amadoras nos telejornais. Primeiramente, viu-se que não há qualquer resistência ao uso de imagens amadoras, ainda que geralmente possuam qualidade técnica inferior. Basta que sejam compreensíveis. Ou seja, mesmo no ambiente em que a qualidade de imagem é primordial, há espaço para a imagem amadora. Quanto à interatividade, verificou-se que os recursos peculiares à TV digital, sobretudo o canal de retorno que permite a comunicação bidirecional, estão disponíveis de modo incipiente. Pode-se afirmar, então, que a implantação da TV digital ainda não trouxe mudanças que relacionam interatividade e utilização de imagens amadoras nos telejornais.

Como todos os editores-chefes entrevistados utilizam imagens amadoras, depreende-se que cada vez mais ganham espaço no telejornal notícias que em outros tempos não iriam ao ar pela inexistência ou indisponibilidade de imagens. Logo, o valor-notícia visualidade adquire maior relevância na medida em que também aumenta a produção de imagens amadoras.

Quanto à abordagem editorial, parece haver um entendimento comum de que se precisa investir no aprofundamento das notícias de telejornal. Certamente, não há como generalizar, porque há perfis e formatos distintos de programas. Mas ficou bem manifesto que o aspecto factual está perdendo espaço para o tratamento da notícia em seu contexto. O fato noticiável deixa de ser fim em si mesmo e passa a ser um propulsor de discussões e análises.

Um dos motivos que levam a essa mudança é a instantaneidade com que notícias são veiculadas em meios como a internet. As imagens amadoras normalmente chegam primeiro aos blogs, sites de notícia e redes sociais, por exemplo, e só depois à televisão. Por isso, limitar-se a uma reexibição não faz mais sentido, segundo a maioria dos editores-chefes entrevistados. Então, essas imagens servem para dar início a uma abordagem mais completa, agregando-se a elas novas informações, referências, contextualizações, opiniões especializadas. E como os telejornais estão circunscritos a um limite de tempo, acredita-se que em prol da qualidade no aprofundamento tende-se a abrir mão da quantidade de notícias.

Outro resultado bastante significativo, concordando com o que se observou no marco teórico, foram as declarações de que está em processo de fortalecimento a prática de jornalismo participativo. Caso se confirme ao longo do tempo, essa pode ser uma transformação capaz de provocar importante impacto social. 
Dessa nova perspectiva, vislumbra-se o fortalecimento do papel do telespectador como participante ativo da produção noticiosa em televisão. Verificou-se, tanto no referencial bibliográfico quanto nas entrevistas com editores-chefes, seu crescente status como coautor das notícias. Se o conteúdo dos telejornais caminha para uma conversação entre emissora e público, para um diálogo, esse discurso em sua forma final tende a transfigurar uma face mais representativa da audiência.

A primeira impressão leva a crer que se trata de uma mudança positiva, afinal, quando se pensa em maior participação popular, sobrevém o pensamento de respeito e valorização dos princípios da democracia. Mas não se pode ser ingênuo. A inclusão de imagens amadoras nos telejornais também pode servir como instrumento de dominação capitalista. No discurso que valoriza a participação e o direito de expressão pode estar velada a pretensão de fidelizar clientes, até mais do que o senso de democratização. Há, também, outro fator a ser ponderado. A atuação do jornalista profissional é determinante no produto que vai ao ar, de tal modo que, por mais intensa que seja a participação do telespectador, sempre haverá um filtro a limitar os "poderes" do olhar amador. Então, mesmo que o enfoque não seja diretamente a obtenção de um benefício no âmbito econômico por parte da emissora, a imagem amadora pode ser usada para a construção de discursos favoráveis a interesses minoritários. Essa prática torna-se ainda mais nociva na medida em que, por esse artifício, a emissora consegue reforçar uma falsa postura de isenção perante determinados fatos.

É necessário frisar que, mesmo entre os editores-chefes que admitiram que a fidelização do telespectador entra em jogo, não transpareceu que defendem este objetivo acima do jornalismo voltado ao bem-estar social. O que ficou explícito é que, de fato, avança-se para uma forma de relacionamento mais próxima entre emissoras e telespectadores.

Diante do diagnóstico obtido por meio da investigação, neste artigo exposto de forma sintetizada, este pesquisador concorda que as mudanças em curso exigem dos profissionais de telejornalismo uma postura em constante revisão. Afinal, assim como a boa prática do jornalismo recomenda "sempre ouvir os dois lados", também é preciso manter um olhar crítico em relação às questões que se colocam como supostas verdades no novo cenário da comunicação.

Pelo que se percebeu, o telejornalismo tende a estar mais aberto ao olhar amador, mas este olhar amador é a personificação do "olhar ideal"? Que outras influências ele revela? Esse ente inserido na cultura do hiper-espetáculo (SILVA, 2014) está apto a direcionar as discussões do jornalismo de televisão, ou é mais um produto dessa cultura moldado por outras forças que não apenas a da mídia? Será que a visão de mundo que ele propõe não precisa ser confrontada com olhares críticos, de modo a tornar socialmente relevante o produto desse jogo dialético? 
É claro que este pesquisador defende que o bom jornalismo é democrático. Apenas reforça o alerta para que não se caia na armadilha de aceitar passivamente a ideia expressa no velho ditado, segundo o qual "a voz do povo é a voz de Deus". O conhecimento sobre a vida social está em permanente construção e desconstrução. Por não ser absoluto, precisa que sobre ele recaiam olhares atentos. Neste caso, amadorismo pode ser um risco.

\section{NOTAS}

1 A realização das entrevistas ocorreu entre novembro de 2014 e fevereiro de 2015. O corpus analisado, portanto, surgiu do grupo de editores-chefes em atividade nesse período: Adriana Krauss (RBS TV/Globo), Andreza Oliveira (RIC/Record), Fabian Londero (RBS TV/Globo), Giovana Borini (RIC/Record), Gregório Silveira (Band SC/Bandeirantes), Gustavo Schwabe (RBS TV/Globo), Karina Koppe (Band SC/Bandeirantes), Marcelo Martins (SBT SC/SBT), Rafaela Arns (RIC/Record), Renata Cavalheiro (SBT SC/SBT).

2 a) Habilidade para comunicar ou mesclar qualquer produto baseado em uma linguagem comum digital; b) Habilidade para comunicar desde o local até o global em tempo real e, vice-versa, para poder diluir o processo de interação; c) Existência de múltiplas modalidades de comunicação; d) Interconexão de todas as redes digitalizadas de bases de dados ou a realização do sonho do hipertexto de Nelson com o sistema de armazenamento e recuperação de dados, batizado como Xanadú, em 1965; e) Capacidade de reconfigurar todas as configurações criando um novo sentido nas diferentes camadas do processo de comunicação; f) Constituição gradual da mente coletiva pelo trabalho em rede, mediante um conjunto de cérebros sem limite algum. Neste ponto, me refiro às conexões entre cérebros em rede e a mente coletiva.

\section{REFERÊNCIAS}

ALSINA, Miquel Rodrigo. A construção da notícia. Petrópolis: Vozes, 2009.

AMORIM, Lidiane Ramirez de. Telespectador multimídia: olhares sobre o jornalismo participativo em noticiários de TV. 2009. 168f. Dissertação (Mestrado em Comunicação Social) Pontifícia Universidade Católica do Rio Grande do Sul. Programa de Pós-Graduação em Comunicação Social, Porto Alegre, 2009.

BACIN, Miro Luiz dos Santos. A fonte amadora na construção de realidades no telejornalismo. 2006. 179f. Tese (Doutorado em Comunicação Social)-Curso de Pós-graduação em Comunicação Social, Pontifícia Universidade Católica do Rio Grande do Sul, Porto Alegre, 2006.

BARDIN, Laurence. Análise de conteúdo. 5.ed. Lisboa: Edições 70, 2010.

BOURDIEU. Sobre a televisão. Rio de Janeiro: J. Zahar, 1997.

BRASIL. Presidência da República. Secretaria de Comunicação Social. Pesquisa brasileira de mídia 2015: hábitos de consumo de mídia pela população brasileira. Brasília: Secom, 2015. 
CANNITO, Newton. A televisão na era digital: interatividade, convergência e novos modelos de negócio. São Paulo: Summus, 2010.

CASTELLS, Manuel. Creativity, innovation and digital culture: a map of interactions. Telos. Cuadernos de Comunicación e Innovación. n. 77. Out-Dic. 2008. Disponível em <http:// telos.fundaciontelefonica.com/telos/articulocuaderno.asp@idarticulo=3.htm > Acesso em 23 set 2014.

CASTRO, Cossete. A Produção de Conteúdos Digitais Interativos como Estratégia para o Desenvolvimento: um breve estudo sobre a experiência latino-americana em TV digital. 2011. Tese. (Pós-doutorado - Cátedra Unesco em Comunicação) - Universidade Metodista de São Bernardo. 2011.

CHARAUDEAU, Patrick. Discurso das mídias. São Paulo: Contexto, 2006.

DTV, Site Oficial da TV Digital Brasileira. Desligamento analógico. Disponível em <http:// www.dtv.org.br/desligamento/> Acesso em 26 set 2014.

DUARTE, Jorge. Entrevista em profundidade. In: BARROS, Antonio; DUARTE Jorge. Métodos e técnicas de pesquisa em comunicação. São Paulo: Atlas, 2005.

FERRAZ, Carlos. Análise e perspectivas da interatividade na TV digital. In: SQUIRRA, Sebastião; FECHINE, Yvana (Orgs.). Televisão digital: desafios para a comunicação. Porto Alegre: Sulina, 2009.

INSTITUTO BRASILEIRO DE GEOGRAFIA E ESTATÍSTICA (IBGE). PNAD 2012. Disponível em <http://www.sidra.ibge.gov.br/bda/tabela/protabl.asp? $\mathrm{c}=1954 \& \mathrm{z}=\mathrm{t} \& \mathrm{o}=1 \& \mathrm{i}=\mathrm{P}>$ Acesso em 29 maio 2014.

KILPP, Suzana. Apresentação. In: FISCHER, Gustavo; MONTAÑO, Sonia; KILPP, Suzana. Impacto das novas mídias no estatuto da imagem. Porto Alegre: Sulina, 2012.

SILVA, Juremir Machado da. Depois do espetáculo: reflexões sobre a tese 4 de Guy Debord. Disponível em <http://www.compos.org.br/data/biblioteca_182.pdf > Acesso em 13 set 2014.

TRAQUINA, Nelson. Teorias do jornalismo: porque as notícias são como são. 2. ed. Florianópolis: Insular, 2005.

VARELA, Juan. Jornalismo participativo: o jornalismo 3.0. In: ORDUÑA, Octavio I. Rojas; ALONSO, Julio; ANTÚNEZ, José Luis; ORIHUELA, José Luis; VARELA, Juan. Blogs: revolucionando os meios de comunicação. São Paulo: Thomson Learning, 2007.

WOLF, Mauro. Teorias das comunicações de massa. São Paulo: Martins Fontes, 2003. 